

https://doi.org/10.31533/pubvet.v14n3a529.1-11

\title{
Fatores intrínsecos a poedeiras comerciais que afetam a qualidade físico-química dos ovos
}

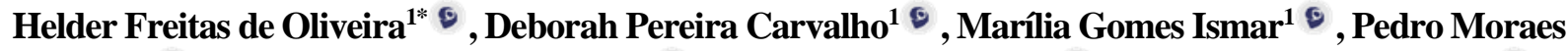 \\ Rezende $^{10}$, Sarah Maria Pires Camargo ${ }^{10}$, Cristielle Nunes Souto ${ }^{2}{ }^{\circ}$, Samuel Brás de Oliveira ${ }^{3}{ }^{\circ}$ \\ ${ }^{1}$ Universidade Federal de Goiás, Departamento de Zootecnia. Goiânia-GO, Brasil. \\ ${ }^{2}$ Universidade Federal de Jataí, Laboratório de Pesquisa em Aquicultura. Jataí-GO, Brasil. \\ ${ }^{3}$ Faculdade Anhanguera de Anápolis, Curso de Psicologia. Anápolis-GO, Brasil. \\ *Autor para correspondência, E-mail: helder@zootecnista.com.br
}

Resumo. O Brasil é o sexto país em produção de ovos no cenário mundial, com uma produção aproximada de 48 bilhões de ovos, movimentando um montante de R\$13,5 bilhões, números que representam a importância do setor para a pecuária nacional. $\mathrm{O}$ principal destino da produção de ovos brasileira é o mercado interno, mercado que detém $99,5 \%$ da produção, estimando um consumo médio de 200 ovos per capita. Aves poedeiras evoluíram significativamente nos últimos anos, graças ao melhoramento genético que proporcionou galinhas mais produtivas, longevas e mais resistentes do ponto de vista sanitário. Além do aumento na produtividade, houve uma melhora no animal como um todo, com maior rusticidade, resistência a patógenos, adaptabilidade aos diversos tipos de clima e ambiente, melhor qualidade de casca até o final de postura, persistência do pico de produção, maior eficiência alimentar e viabilidade. Mas para que todo esse potencial genético seja bem aproveitado, é vital que haja um correto manejo das aves, sendo de fundamental importância que esses animais tenham seu plano nutricional adequado, levando em consideração sua idade, programa de luz, programa de vacinas, instalações adequadas de acordo com o sistema de produção, que ofereça as condições ambientais necessárias ao conforto das aves, água potável e de qualidade, entre outros. E levar em consideração também os cuidados com o produto final, com coletas periódicas, seleção e armazenamento, pois tudo isso irá refletir tanto na eficiência produtiva, como na qualidade do produto produzido. Objetivou-se com esta revisão bibliográfica, abordar sobre os principais aspectos relacionados aos fatores que afetam à qualidade de ovos.

Palavras chave: galinhas, manejo, nutrição, qualidade de ovo, sanidade

\section{Factors intrinsic to laying hens that affect the physicochemical quality of eggs}

Abstract. Brazil is the sixth country in egg production in the world scenario, with an approximate production of 48 billion eggs, moving an amount of $\mathrm{R} \$ 13.5$ billion, figures that represent the importance of the sector for domestic livestock. The main destination of Brazilian egg production is the domestic market, which holds $99.5 \%$ of production, with an estimated average consumption of 200 eggs per capita. Laying birds have evolved significantly in recent years, thanks to the genetic improvement that has provided more productive, long-lived and more health-resistant chickens. Besides the increase in productivity, there was an improvement in the animal as a whole, with greater rusticity, resistance to pathogens, adaptability to different types of climate and environment, better bark quality until the end of laying, persistence of peak production, greater efficiency. food and viability. But in order for this genetic potential to be fully utilized, it is vital that the birds are properly managed, and it is of fundamental importance 
that they have their proper nutritional plan, taking into account their age, light program, vaccine program, appropriate facilities. according to the production system, which offers the environmental conditions necessary for the comfort of birds, drinking water and quality, among others. And also take into account the care of the final product, periodic collection, selection and storage, as all this will reflect both the productive efficiency and the quality of the product produced. The aim of this bibliographic review was to address the main aspects related to the factors that affect egg quality.

Keywords: chickens, management, nutrition, egg quality, health

\section{Factores intrínsecos a las gallinas ponedoras que afectan la calidad fisicoquímica de los huevos.}

Resumen. Brasil es el sexto país en producción de huevos en el escenario mundial, con una producción aproximada de 48 mil billones de huevos, moviendo una cantidad de R \$ 13.5 mil millones, cifras que representan la importancia del sector para la pecuaria nacional. El principal destino de la producción brasileña de huevos es el mercado interno, que posee el $99.5 \%$ de la producción, con un consumo promedio estimado de 200 huevos per cápita. Las aves ponedoras han evolucionado significativamente en los últimos años, gracias a la mejora genética que ha proporcionado aves más productivas, longevas y más resistentes desde el punto de vista sanitario. Además del aumento de la productividad, hubo una mejora en el animal en su conjunto, con mayor rusticidad, resistencia a los patógenos, adaptabilidad a diferentes tipos de clima y medio ambiente, mejor calidad de la corteza hasta el final de la postura, persistencia de la producción máxima, mayor eficiencia alimentar y viabilidad. Pero para que este potencial genético se utilice plenamente, es vital que las aves se manejen adecuadamente, y es de fundamental importancia que tengan su plan nutricional adecuado, teniendo en cuenta su edad, programa de luz, programa de vacuna, instalaciones apropiadas. según el sistema de producción, que ofrece las condiciones ambientales necesarias para la comodidad de las aves, el agua potable y de calidad, entre otros. Y también tenga en cuenta el cuidado del producto final, la recolección periódica, la selección y el almacenamiento, ya que todo esto reflejará tanto la eficiencia productiva como la calidad del producto producido. El objetivo de esta revisión bibliográfica fue abordar los principales aspectos relacionados con los factores que afectan la calidad del huevo.

Palabras clave: gallinas, manejo, nutrición, calidad del huevo, sanidad

\section{Introdução}

A avicultura de postura é um segmento do setor avícola que tem se destacado, nos últimos cinco anos cresceu aproximadamente 17,01\% na produção de ovos, saltando de 34,13 bilhões de unidades em 2013 para 39,92 bilhões em 2017, acima dos crescimentos registrados por outros segmentos avícolas nesse mesmo período. $\mathrm{O}$ aumento da produção relaciona-se com o aumento do consumo per capita de ovo de galinha, que avançou $14,28 \%$ durante este mesmo período, partindo de 168 para 192 unidades (ANUALPEC, 2019). Grande parte deste crescimento se deu graças ao desaparecimento do estigma de que o consumo diário de ovo traria problemas de saúde devido ao colesterol que foi amplamente difundido na década de 90 .

O ovo é um alimento essencial na composição da dieta humana e considerado uma proteína de alto valor biológico. Além disso, é um alimento de baixo custo e acessível para o consumidor de menor poder aquisitivo, sendo que as características físicas e químicas do ovo podem influenciar o seu grau de aceitabilidade no mercado e também agregar valor ao produto comercializado (Freitas et al., 2011).

No entanto, para que todo esse potencial nutritivo possa ser explorado por seres humanos, os ovos devem ser conservados durante o período de comercialização, já que podem passar semanas a partir do momento da postura, até que sejam comprados e consumidos (Pascoal et al., 2008). Logo após a postura do ovo, começam a ocorrer mudanças, fenômeno inevitável, que reduz sua qualidade e, eventualmente, 
causa sua deterioração (Giampietro-Ganeco et al., 2012). Corroborando, Oliveira \& Oliveira (2013) afirmam que o ovo, desde a sua formação, está sujeito a influências intrínsecas como genética, idade, condição nutricional e sanitária da poedeira, e fatores externos tais como o clima e manejo, que podem alterar as características dos ovos, resultando em degradação de seus componentes, modificando suas propriedades funcionais e comprometendo sua eficiência como alimento natural ou matéria-prima.

Portanto, torna-se indispensável o conhecimento sobre os efeitos destas alterações sobre a qualidade físico-química de ovos comerciais. Objetivou-se com esta revisão bibliográfica, abordar sobre os principais aspectos relacionados aos fatores que afetam à qualidade de ovos.

\section{Genética}

Características economicamente importantes como peso do ovo, idade à maturidade sexual, peso corporal, fertilidade, eclodibilidade e taxa de nascimento, assim como àquelas relacionadas à qualidade do ovo como tamanho e razão altura/largura devem ser levadas em consideração nos programas de melhoramento genético de aves de postura, por estarem associadas diretamente à produção de ovos e à integridade do produto durante o transporte e armazenamento (Lopes et al., 2011; Oliveira et al., 2001). Assim, o monitoramento contínuo dessas características por meio de estimativas de parâmetros genéticos tem como finalidade garantir elevado padrão de qualidade do ovo e seus subprodutos atendendo assim as exigências do mercado mundial (UBA, 2008).

Coloração e outras características da casca, bem como o peso médio dos ovos, são as principais características de qualidade inerentes à influência genética, diferindo dos vários híbridos comerciais disponíveis no mercado (Oliveira \& Oliveira, 2013), sendo o ovo segundo a coloração da sua casca classificado em branco e vermelho (ou marrom). Poedeiras de origem da raça Leghorn branca dão origem aos ovos com casca branca, já as aves de origem das raças Rhodes Island Red, New Hampshire e Leghorn vermelha, originam ovos de casca marrom. As duas poedeiras são híbridas e possuem características fisiológicas idênticas, sendo que as que produzem ovos marrons são um pouco mais pesadas no início de postura e pouco menos eficiente em relação às brancas (Honorato et al., 2016).

A coloração da casca está relacionada com a deposição de pigmentos derivados do anel de porfirina, onde apesar de poedeiras brancas produzirem tal pigmento, a deposição na parte mais externa da casca é praticamente irrisória, se comparado às aves de ovos vermelhos. Do ponto de vista nutricional, não há diferença entre ovos brancos e os vermelhos, ambos são igualmente ricos em proteínas, vitaminas e sais minerais. No entanto, segundo (Cavero et al., 2012) relatam que o consumidor avalia a qualidade de um ovo de acordo com suas demandas subjetivas específicas, e uma dessas demandas é claramente cor da casca do ovo.

Há diferença de preço entre eles, ovos vermelhos são normalmente mais caros, pois aves que os produzem, são galinhas semipesadas que consomem mais ração que uma ave leve, que são as produtoras de ovos brancos. Mas também o preço dos ovos é determinado pelo mercado, já que eles são mais procurados pelos consumidores, que muitos acreditam, erradamente, que os ovos escuros têm mais vitaminas na gema (Brandão et al., 2014; Cavero et al., 2012).

\section{Nutrição}

Diante da evolução genética que ocorreu nas últimas décadas com relação às aves de postura, onde ocorreu melhora na produção de ovos, qualidade, persistência de pico, aliado a menores taxas de conversão alimentar e maior tempo em produção, às galinhas poedeiras tornaram-se também animais mais exigentes nutricionalmente.

$\mathrm{O}$ grande desafio de dominar o dinamismo da genética tornou as aves muito mais sensíveis às variações dos níveis nutricionais na dieta. A nutrição busca não só a eficiência na produção de ovos, mas também que os mesmos sejam de boa qualidade. Deste modo, é preciso atenção quanto às fases de criação das poedeiras (cria, recria, pré-postura, postura), a linhagem que está sendo trabalhada (leve ou semipesada) e também a idade da ave (ração de postura 1, postura 2 etc.), assim oferecendo às aves rações de acordo com sua exigência nutricional específica, o que irá proporcionar não só um melhor desempenho zootécnico, como também otimizará a qualidade do produto final que é o ovo. 
Assim, a suplementação mineral tornou-se essencial na nutrição de poedeiras. Em virtude dos avanços no melhoramento genético, nutrição, fatores de ambiência e manejo, torna-se necessária a revisão periódica das exigências de cálcio $(\mathrm{Ca})$ para poedeiras, uma vez que este mineral é fundamental para o desenvolvimento ósseo durante a fase de crescimento da ave e para formação da casca do ovo durante a postura, além de participar nos processos metabólicos.

$\mathrm{Na}$ avicultura de postura atualmente ocorrem grandes perdas devido ao mau processamento ou má qualidade do produto, principalmente devido à má qualidade da casca, o que está relacionado com a nutrição das aves. Para boa nutrição é necessário que o animal receba quantidades adequadas de nutrientes, incluindo-se minerais, que são considerados de grande importância para as aves, pois participam de processos bioquímicos corporais (Sechinato et al., 2006). Corroborando, Carvalho (2012) afirma ainda, que minerais estão diretamente relacionados com o desempenho das aves, influenciando taxa de postura, peso dos ovos, conversão alimentar e ganho de peso. Na produção do ovo ocorre uma perda especialmente grande de cálcio. A casca representa de 9 a $10 \%$ do peso do ovo. É constituída por 90\% dos minerais dos quais 98\% são cálcio em forma de carbonato de cálcio, e em pequenas quantidades têm-se, fósforo, magnésio, sódio, potássio, zinco, manganês, ferro e cobre (Farmer et al., 1983; $\underline{\text { Silva \& }}$ Santos, 2000).

Além dos minerais, a proteína e os aminoácidos possuem papel importante na calcificação da casca, participando de processos essenciais de sustentação e modelagem da estrutura calcária. Deve ser evidenciada a qualidade da proteína da dieta, a qual deve conter os aminoácidos essenciais balanceados, principalmente metionina (Brandão et al., 2014; Guinotte \& Nys, 1991). A água também apresenta papel importante na qualidade da casca do ovo, quando os íons de $\mathrm{Cl}$ e $\mathrm{Na}$ estão em concentrações elevadas, percebe-se o aumento nas ocorrências de ovos defeituosos (Mazzuco et al., 1998).

A biodisponibilidade do mineral varia de acordo com o tipo da fonte mineral. As fontes de minerais, mais comumente utilizadas na nutrição animal são as fontes inorgânicas de origem geológica ou industrial. Uma suplementação mineral inadequada durante a fase de crescimento terá como consequência um desequilíbrio na homeostase mineral e desenvolvimento inapropriado dos ossos das aves. O principal sintoma de deficiência de cálcio e fósforo é, além de um menor desempenho das aves, o aparecimento de ossos e bicos frágeis, porém, o cálcio em excesso pode agir como antagonista dificultando a absorção de alguns minerais.

Para poedeiras o tamanho da partícula de cálcio e sua origem assumem diferenças na sua liberação e absorção durante o processo de formação da casca. O carbonato de cálcio sendo utilizado como principal fonte de cálcio, quando possui uma maior granulometria, apresenta melhor resistência e estabilidade para a casca, isso é possível, pois o mesmo fica mais tempo no trato digestivo, gerando efeito benéfico na espessura da casca. $\mathrm{O}$ tamanho da partícula é muito importante, pois se o calcário for muito fino, o cálcio passa na moela rapidamente, não ficando disponível no momento em que a ave está formando a casca do ovo. O cálcio quando está em excesso, interfere no metabolismo do fósforo, zinco, manganês e ferro. Buscando sempre atingir uma alta qualidade para a casca, os níveis de cálcio vs. fósforo devem ser de acordo com a idade e o consumo (Jardim Filho et al., 2005). Esses dois compostos, além de grande importância na produção, podem ser considerados reguladores de ingestão de alimentos. Além disso, a razão entre cálcio, fósforo e vitamina D3 e disponibilidade da fonte de cálcio, interferem diretamente nas exigências de cálcio para as poedeiras (NRC, 1994). Estudos dessa natureza também têm repercussão nos aspectos econômicos das rações e contribuem para minimizar os custos de produção e reduzir possíveis impactos no meio ambiente.

\section{Idade}

Diversos autores abordam sobre as influências que a idade da poedeira tem na qualidade dos ovos, afirmam que a idade da ave influencia diretamente na qualidade física do ovo, alterando a relação gema/albúmen, onde este índice aumenta em ovos maiores de aves mais velhas e também explicitam que há um decréscimo na qualidade da casca do ovo com o aumento da idade das aves (Alves et al., 2007; Carvalho et al., 2013; Menezes et al., 2012). Similarmente, Duarte (2016) afirma que à medida que a poedeira envelhece, há uma queda natural na produção e na qualidade interna e externa dos ovos. Ao final do primeiro ciclo de postura, a casca dos ovos perde em espessura e resistência, justamente quando o peso dos ovos é maior. 
$\mathrm{O}$ aumento no tamanho dos ovos favorece a redução na qualidade da casca, pois a taxa do aumento do peso de ovo é superior à taxa de aumento no volume da casca com o avançar da idade das aves. Outro fator é a diminuição na espessura da casca pelo aumento do número e do diâmetro dos poros, favorecendo trocas gasosas entre o ovo e o meio (Alves et al., 2007). Sendo assim, a percentagem de casca é afetada pela idade da poedeira, aves mais jovens apresentam maior percentagem de casca em relação as mais velhas (Ramos et al., 2012). O decréscimo da qualidade da casca, com a idade, é devido à queda de habilidade da poedeira na absorção de cálcio intestinal e mobilização do cálcio ósseo. A taxa de retenção de cálcio em poedeiras jovens é de $60 \%$, enquanto que em poedeiras mais velhas essa taxa cai para 40\% (Keshavarz \& Nakajima, 1993).

Vilela (2012) constatou que o peso dos ovos aumentou com o avanço da idade da ave assim como a espessura da casca diminuiu quando a ave se tornou mais velha. O percentual de albúmen aumentou, enquanto a percentagem de proteína e $\mathrm{pH}$ do albúmen diminuíram ao longo das idades avaliadas $(30,50$ e 70 semanas de vida). Percentagem da gema, umidade e $\mathrm{pH}$ diminuíram com o aumento da idade da poedeira, enquanto proteína bruta e extrato etéreo aumentaram. Ao avançar a idade da poedeira, o peso do ovo e a percentagem da gema aumentam enquanto que as percentagens de casca e albúmen diminuem. Dessa forma, os ovos produzidos por aves mais velhas podem apresentar qualidade de casca inferior, de forma a interferirem negativamente na qualidade interna dos mesmos (Garcia et al., 2010).

As aves velhas, assim como aquelas que produzem ovos com casca de qualidade ruim, têm menor atividade da enzima anidrase carbônica, o que leva a menor calcificação da casca do ovo. Em todo o ciclo de postura a quantidade de cálcio depositada nos ovos é mais ou menos constante. Porém, do início ao fim da postura, o ovo aumenta até $40 \%$ do seu tamanho, logo a quantidade de cálcio por superfície de casca é menor, o que resulta em uma casca com menor resistência a quebra. Outro fator que pode estar relacionado à baixa qualidade da casca de aves mais velhas é a baixa capacidade de hidroxilização da vitamina D nos rins em galinhas velhas (Araújo et al., 2011; Lichovnikova, 2007).

A idade influencia a qualidade interna do ovo, o albúmen torna-se mais líquido em ovos de aves mais velhas, perdendo características, como capacidade de formação de espuma. Unidade Haugh, índice de gema e altura de albúmen também diminuem de acordo com a idade das aves. As sequências de postura tornam-se mais curtas, aumentando o intervalo entre ovulações, esta redução na taxa de postura é acompanhada do aumento no tamanho do ovo, pois a mesma quantidade de gema proveniente da síntese hepática é depositada em um número cada vez menor de folículos, devido a maior capacidade das aves velhas de transferir lipídeos para a gema (Lopes et al., 2011; Molino et al., 2012; Pissinati et al., 2014; Van Den Brand et al., 2004; Vieira \& Bertechini, 2001).

\section{Ambiência}

O ambiente de produção é um dos principais causadores de perdas na produção animal em escala industrial. Em relação à variável temperatura do ar, esta se apresenta como o principal fator do ambiente causador de perdas (Vitorasso \& Pereira, 2009). A interação animal e ambiente deve ser considerada quando se busca maior produtividade e as diferentes respostas do animal às peculiaridades de cada região são determinantes no sucesso avícola (Oliveira et al., 2014).

Como os galpões avícolas brasileiros não são termicamente isolados, as amplitudes críticas de temperatura e umidade externas são imediatamente transferidas para o interior, podendo provocar altos índices de mortalidade, além de prejudicar o desempenho produtivo e piorar a qualidade dos ovos (Silva et al., 2012). Oliveira \& Oliveira (2013) relatam que altas temperaturas causam desconforto térmico para as poedeiras, diminuindo o consumo de ração e consequentemente a concentração sanguínea de cálcio que seria fornecido para a formação da casca do ovo. Pode ocorrer ainda o fenômeno da hiperventilação e a alcalose respiratória pela redução do nível de dióxido de carbono $\left(\mathrm{CO}_{2}\right)$ no sangue, que é importante para a síntese de carbonato de cálcio, influenciando diretamente na espessura da casca do ovo. Desta forma, é de extrema importância que se lance mão de recursos para propiciar o ambiente adequado aos animais, para que as mesmas possam expressar o seu potencial produtivo, produzindo ovos de qualidade. A zona de conforto térmico deve estar entre $20^{\circ} \mathrm{C}$ e $30 \mathrm{C}$, pois segundo Vitorasso \& Pereira (2009) havendo estresse térmico, o desempenho das aves pode ser afetado, acarretando diminuição da ingestão de alimento e das atividades físicas, além de perdas na produção, tais como diminuição na quantidade de ovos produzidos, aumento dos ovos com má formação e até o óbito das aves. 
É visível a influência que o ambiente tem sobre a qualidade de ovos. Oliveira et al. (2014) observaram que poedeiras quando submetidas a estresse térmico, apresentaram menor consumo de ração, menor taxa de postura, ovos mais leves de casca mais fina e com unidade Haugh menor do que os grupos de aves criados em zona de conforto térmico. Os resultados observados neste estudo corroboram com o que a literatura relata sobre o tema, que animais submetidos a condições ambientais dentro de sua zona de conforto térmico, proporcionam ao sistema de produção melhores índices produtivos e parâmetros de qualidade.

\section{Sanidade e profilaxia de instalações e equipamentos}

A indústria avícola brasileira cresce anualmente e se torna cada vez mais representativa na produção e exportação dos seus produtos. Os cuidados com a sanidade têm acompanhado e favorecido essa evolução, entretanto, patógenos continuam a provocar grandes prejuízos à avicultura. $\mathrm{Na}$ aquisição das galinhas, deve-se ter certeza de sua procedência para evitar a contaminação de toda uma granja. As doenças destas aves têm as mais variadas origens e agentes causais como vírus, bactérias, fungos e parasitas (Oreng \& Evans, 1990; Ronchi, 2004).

O estado sanitário dos plantéis vai influenciar diretamente na qualidade dos ovos. A bronquite infecciosa e a micoplasmose são enfermidades de grande importância para estes estabelecimentos, visto que causam deformações, descoloração e fragilidade na casca e nos seus compostos internos (Oliveira \& Oliveira, 2013). Oreng \& Evans (1990) e Ronchi (2004) ressaltam que outras doenças também se destacam quando o assunto é poedeira comercial, dentre as causadas por bactérias estão: a salmonelose, colibacilose, coriza infecciosa, cólera, clostridiose, estafilococose, estreptococose, os vírus causam laringotraqueíte, gumboro, Newcastle, influenza, bouba aviária, Marek, leucose linfoide e encefalomielite aviária. Entre as enfermidades passíveis de atingir aves de postura, as doenças respiratórias são as mais preocupantes, pedindo uma atenção especial do produtor durante o período de imunização. Doenças fúngicas e parasitoses também podem acometer estas aves e diminuir significativamente a qualidade dos ovos produzidos por elas.

A limpeza e desinfecção das gaiolas sejam elas convencionais ou automáticas também interfere na qualidade do ovo. Portanto, é preciso observar se estão adequadas à inclinação, flexibilidade e malha do piso bem como o funcionamento e higienização dos cintos coletores, descedouros e esteiras, principalmente nos pontos de transição entre eles (Oliveira \& Oliveira, 2013). Pois sujeiras encontradas nos ovos, advindas de ferrugens das gaiolas não causam perda da qualidade nutricional; porém, tornam os ovos visualmente feios e indesejados pelo consumidor, além do mais quando estas sujeiras são provenientes de resíduos de insetos e/ou ácaros, pode iniciar a perda de qualidade, do ponto de vista microbiológico do alimento, tornando-o impróprio para consumo ou reduzindo seu tempo de prateleira. Outro fator que tem ligação direta com a qualidade físico-química do ovo está relacionado à qualidade da água. Segundo Gama et al. (2008) para as aves, a água é considerada o nutriente essencial mais importante, pois é necessário em maior volume, sendo consumida em pequenas quantidades, porém com muita frequência. Também é utilizada na higiene das instalações e como veículo de vacinas, medicamentos e nutrientes. O uso de água de qualidade duvidosa pode interferir nos índices zootécnicos e na disseminação de enfermidades, acarretando graves prejuízos econômicos, além de carrear agentes patogênicos de doenças de interesse em saúde pública.

Para o sucesso da produção, além de trabalhar com boa genética, é preciso levar em consideração outros fatores, como manejo ambiental, nutricional e sanitário, sendo este último muitas das vezes esquecido ou ignorado. Apesar de ter acontecido, ao longo dos anos, um aumento significativo da rusticidade das atuais aves de postura, ainda são vulneráveis a determinadas situações e a prevenção e profilaxia continuam sendo os métodos mais efetivos para evitar doenças e consequentemente prejuízo na produção. Assim sendo, é importante que protocolos de biosseguridade sejam executados nas granjas comerciais, envolvendo não só questões de limpeza, desinfecção e isolamento, mas também um bom programa de vacinação (Tabela 1) desde o incubatório até o alojamento, englobando todo o período produtivo dessas aves. 
Tabela 1. Cronograma de vacinação de granja de postura

\begin{tabular}{lcc}
\hline Idade & Doença & Via de aplicação \\
\hline 1 dia (incubatório) & Marek + Gumboro + Bouba (suave) & Subcutânea \\
7 dias & New Castle (B1) + Bronquite Infecciosa (H120) + Gumboro & Ocular \\
35 dias & Bouba (forte) & Membrana da asa \\
35 dias & New Castle (LS) + Bronquite Infecciosa (H52) + Gumboro & Ocular \\
50 dias & Coriza Infecciosa (Aquosa) & Intramuscular \\
70 dias & New Castle (LS) + Bronquite Infecciosa (H52) + Gumboro & Ocular \\
100 dias & Encefalomielite Aviária & Água de bebida \\
120 dias & Coriza Infecciosa (Oleosa) & Intramuscular \\
135 dias & New Castle + Gumboro + Bronquite Infecciosa (Tríplice Oleosa) & Intramuscular \\
Fonte: Portal Suínos e Aves & &
\end{tabular}

\section{Manejo}

Para a boa qualidade do ovo e principalmente da casca do ovo, o manejo ideal é de fundamental importância. Dentre os fatores que podem influenciar na melhoria na qualidade da casca do ovo e na produtividade de um lote de poedeiras, destacam-se os programas de luz, debicagem, controle de peso das aves, temperatura no ambiente de criação, transporte e densidade $\left(\mathrm{n}^{\circ}\right.$ de aves por $\left.\mathrm{m}^{2}\right)$.

\section{Controle de peso das aves}

Para iniciar a fase de postura na idade e peso adequados, com condições fisiológicas e corporais adequadas é importante o acompanhamento semanal da evolução do ganho de peso do lote durante a fase de cria e recria. A obtenção do peso médio do lote possibilita a comparação com os valores de peso padrão para a idade da ave, cada linhagem possui um padrão diferente. O controle de peso corporal possibilita manter os lotes uniformes. A uniformidade do lote está ligada ao manejo e à alimentação praticados e sua variação terá influência no seu desempenho produtivo (Oliveira et al., 2001). Corroborando, Avila et al. (2011) afirmam que durante as fases de cria e recria das frangas, devem-se utilizar práticas de manejo que favoreçam a menor variabilidade no peso corporal, obtendo-se como consequência uma boa uniformidade do lote, isto tem como objetivo preparar as aves adequadamente, para que as mesmas expressem do máximo da sua capacidade produtiva de acordo com a potencialidade genética de cada linhagem.

Deste modo, a cria e recria de poedeiras, deve ser realizada principalmente de acordo com o que preconiza os manuais de linhagem, pois isso não só otimizará a produção, como também melhorará a qualidade dos ovos produzidos, reduzindo principalmente a desuniformidade no tamanho dos ovos, já que dependendo do tamanho e/ou peso do ovo, o mesmo terá maior ou menor valor final.

\section{Densidade}

O dimensionamento do número de aves/gaiola é de extrema importância. A disputa por espaço influência o consumo de ração, o que piora a conversão alimentar, ocasionando retardamento do desenvolvimento corporal, queda de uniformidade e canibalismo, além do estresse que aumenta o número de ovos bicados e prejudica a produção e a qualidade dos ovos (Mazzuco et al., 1998).

Menezes et al. (2009) afirmam ainda que a existem diferenças quanto ao peso dos ovos dependendo da densidade utilizada, com tendência de aumento do peso dos ovos a medida que o número de aves por $\mathrm{m}^{2}$ diminuiu. Similarmente Benyi et al. (2006) afirmam que densidades menores, ou seja, com grupos de duas, três ou quatro galinhas por gaiola e densidade de 1100,733 ou $550 \mathrm{~cm}^{2}$ por ave, produzem ovos mais pesados quando relacionados a grupos de alta densidade. Corroborando, Pavan et al. (2005) estudaram densidade de alojamento entre 562,15 e $375,00 \mathrm{~cm}^{2} /$ ave e observaram diminuição no peso dos ovos à medida que diminuíram o espaço das aves nas gaiolas.

\section{Debicagem}

Um aspecto importante em poedeiras alojadas em gaiolas convencionais é a alta incidência da bicagem, principalmente em lotes submetidos a situações de estresse (Bastos-Leite et al., 2016). A casca do ovo é uma das primeiras variáveis afetadas em caso de bem-estar comprometido, portanto, há 
indicativo de que o bem-estar das aves melhora com a debicagem. A debicagem é prática comum na avicultura de postura e tem como objetivo melhorar o desempenho produtivo da ave, conversão alimentar, uniformidade do lote, prevenir o canibalismo e a bicagem dos ovos (Avila et al., 2011). Além disto, aves submetidas à debicagem apresentam comportamento menos agressivo, melhoria da taxa de postura e redução dos ovos bicados e de mortalidade (Laganá et al., 2011).

Na produção industrial de poedeiras, normalmente são realizadas duas debicagens, a primeira entre sete e dez dias de vida e a segunda, entre doze a quatorze semanas de idade (Avila et al., 2011; Laganá et al., 2011). Deste modo, o principal efeito positivo da debicagem na qualidade da casca é indireto, uma vez que lotes debicados corretamente são mais tranquilos e os danos da casca são minimizados em lotes não perturbados no período de postura.

\section{Programa de luz}

A luz influencia o desenvolvimento reprodutivo da ave, as mesmas são estimuladas via fotoreceptores hipotalâmicos com o aumento de luz. Tendo em vista sua influência direta sobre o sistema reprodutivo, desempenho e produção de ovos, torna-se de suma importância à adequação do programa de iluminação, uma vez que o manejo incorreto deste, pode refletir na maturidade sexual da ave e na qualidade dos ovos (Nunes et al., 2013).

A luz tem forte influência na produção hormonal dos órgãos reprodutores das aves. A luz penetra no globo ocular e estimula a hipófise a produzir os hormônios responsáveis pelo processo reprodutivo (Hormônio foliculoestimulante - FSH e Hormônio Luteinizante - LH) (Gewehr, 2012). Atualmente, o programa de luz é formatado conforme as características de cada linhagem. Cada linhagem tem sua particularidade genética, o que deve ser obedecido na realização de um programa de iluminação.

Tanto no que se refere ao fotoperíodo, quanto na intensidade, à luz tem papel importante no desempenho de lotes de poedeiras e pode produzir efeitos tanto no tamanho dos ovos produzidos, como na persistência do pico de postura. O fornecimento apropriado do regime luminoso pode alterar os desempenhos produtivos da poedeira, como antecipar ou retardar a postura; a taxa de postura pode ser influenciada e seu intervalo alterado; a qualidade da casca pode ser melhorada e o tamanho do ovo pode ser otimizado. Confirmando, Araújo et al. (2011) afirmam que um programa de luz adequado a linhagem utilizada pode propiciar melhor qualidade da casca do ovo, menor número de ovos de duas gemas e deformados, e menor mortalidade por prolapso.

\section{Transporte}

O ovo tem que percorrer desde o momento da postura um longo percurso, passando pela coleta, limpeza, classificação, estocagem, e embalagem ou quebra, ate a aquisição pelo consumidor. Logo as oportunidades da casca sofrer algum dano são grandes, assim todas as medidas quanto ao ajuste de equipamentos e treinamentos de pessoal, devem ser tomadas de modo à obtenção do melhor resultado produtivo possível.

A coleta deve ser feita de 3 a 4 vezes por dia, pois isso resulta em menor incidência de ovos quebrados, sujidades e, consequentemente, menor contaminação dos ovos. Na coleta dos ovos recomenda-se o uso de bandejas de plástico. Os ovos devem ser colocados nas bandejas com as pontas finas para baixo. Durante o transporte dos ovos para a agroindústria, deve ser realizado o empilhamento de no máximo oito bandejas, pois isso diminui a pressão nas bandejas inferiores e assim reduz os índices de quebra dos ovos durante o transporte. Além disso, pode-se proteger o ovo contra a quebra com a utilização de isopor ou polpa (Mazzuco et al., 2006).

\section{Considerações finais}

É imprescindível que em toda granja de ovos seja dada a devida atenção às aves no que tange a sua nutrição, oferecendo rações que atendam as sua exigências nutricionais em cada fase da sua vida, e de acordo com a linhagem selecionada, é preciso ainda proporcionar um ambiente com conforto térmico, programa de vacinação, higiene e profilaxia, manejo correto da ave, e também o correto manuseio dos ovos (frequência de coleta). Pois quando todos estes fatores são levados em consideração, é possível 
produzir ovos de qualidade, com casca limpa e íntegra, com proporção adequada de seus componentes internos, aumentando assim a qualidade do alimento e prolongando assim sua vida útil na prateleira.

\section{Referências bibliográficas}

Alves, S. P., Silva, I. J. O., \& Piedade, S. M. S. (2007). Avaliação do bem-estar de aves poedeiras comerciais: efeitos do sistema de criação e do ambiente bioclimático sobre o desempenho das aves e a qualidade de ovos. Revista Brasileira de Zootecnia, 36(5), 1388-1394. https://doi.org/http://dx.doi.org/10.1590/S1516-35982007000600023.

ANUALPEC. (2019). Anuário da Pecuária Brasileira (20th ed., Vol. 1). Instituto FNP.

Araújo, W. A. G., Albino, L. F. T., TAVERNARI, F. de C., \& GODOY, M. J. de S. (2011). Programa de luz na avicultura de postura. Rev. CFMV , 52, 58-65.

Avila, V. S., Rosa, P. S., Roll, V. F. B., \& Catalan, A. A. S. (2011). Debicagem em galinhas poedeiras. Avicultura Industrial, 1, 16-20.

Bastos-Leite, S. C., Gomes, J. V., Alves, M. G. M., Goulart, C. C., Silva, J. D. B., \& Medeiros, F. M. (2016). Desempenho produtivo e qualidade de ovos de poedeiras leves submetidas a diferentes níveis de debicagem. Acta Veterinaria Brasilica, 10(2), 110-115.

Benyi, K., Norris, D., \& Tsatsinyane, P. M. (2006). Effects of stocking density and group size on the performance of white and brown Hyline layers in semi-arid conditions. Tropical Animal Health and Production, 38(7-8), 619-624.

Brandão, M. D. M., Santos, F. F., Machado, L. S., Verinaud, M. S., Oliveira, J. M., Soares, N. M., Nascimento, E. R., \& Pereira, V. L. A. (2014). The effect of eggshell apex abnormalities on table egg quality during storage in 2 seasons of the year. Poultry Science, 93(10), 2657-2662. https://doi.org/http://dx.doi.org/10.3382/ps.2014-03991.

Carvalho, L. S. S. (2012). Nutrição de poedeiras em clima quente. Revista Científica Eletrônica de Medicina Veterinária, 18, 1-15.

Carvalho, J. X., SUárez, R. O., Mendes, F. Q., Fernandes, R. V. B., Cunha, M. C., \& Carvalho, A. M. X. (2013). Extensão da vida de prateleira de ovos pela cobertura com própolis. Semina: Ciências Agrárias, 34(5).

Cavero, D., Schmutz, M., Icken, W., \& Preisinger, R. (2012). Attractive eggshell color as a breeding goal. Lohmann Information, 47(2), 15-21.

Duarte, C. A. H. G. 2016. O efeito do peso vivo às 17 semanas de idade de galinhas poedeiras nos parâmetros produtivos e de qualidade do ovo durante a fase de postura. Dissertação de Mestrado, Universidade de Lisboa, Lisboa, Portugal.

Farmer, M., Roland Sr, D. A., \& Eckman, M. K. (1983). Calcium metabolism in broiler breeder hens. 2 . The influence of the time of feeding on calcium status of the digestive system and eggshell quality in broiler breeders. Poultry Science, 62(3), 465-471.

Freitas, L. W., Paz, I. C. de L. A., Garcia, R. G., Caldara, F. R., Seno, L. de O., Felix, G. A., Lima, N. D. da S., Ferreira, V. M. O. dos S., \& Cavichiolo, F. (2011). Aspectos qualitativos de ovos comerciais submetidos a diferentes condições de armazenamento. Revista Agrarian, 4(11), 66-72. https://doi.org/http://ojs.ufgd.edu.br/index.php/agrarian/article/view/998.

Gama, N., Togashi, C. K., Ferreira, N. T., Buim, M. R., Guastalli, E. L., \& Fiagá, D. A. M. (2008). Conhecendo a água utilizada para as aves de produção. Biológico, 70(1), 43-49.

Garcia, E. R. M., Orlandi, C. C. O., Oliveira, C. A. L., Cruz, F. K., Santos, T. M. B., \& Otutumi, L. K. (2010). Qualidade de ovos de poedeiras semipesadas armazenados em diferentes temperaturas e períodos de estocagem. Revista Brasileira de Saúde e Produção Animal, 11(2), 505-518. https://doi.org/http://revistas.ufba.br/index.php/rbspa/article/view/1703/986.

Gewehr, C. E. (2012). Programas de iluminação para poedeiras semi-pesadas. Biotemas, 25(1), 151157.

Giampietro-Ganeco, A., Scatolini-Silva, A. M., Borba, H., Boiago, M. M., Lima, T. M. A., \& Souza, P. A. (2012). Estudo comparativo das caracteristicas qualitativas de ovos armazenados em refrigeradores domésticos. Arquivos de Veterinária, 28(2), 100-104. 
Guinotte, F., \& Nys, Y. (1991). Effects of particle size and origin of calcium sources on eggshell quality and bone mineralization in egg laying hens. Poultry Science, 70(3), 583-592. https://doi.org/https://doi.org/10.3382/ps.0700583.

Honorato, C. A., Seabra, B. S., Siqueira, M. S., Melgarejo, M. R., \& Fraga, T. L. (2016). Qualidade e características físicas de ovos comerciais. Nucleus Animalium, 8(2), 29-36.

Jardim Filho, R. M., Stringhini, J. H., Café, M. B., Leandro, N. S. M., Cunha, W. C. P., \& Nascimento, J. (2005). The influence of limestone source and particles sizes on performance and eggshell quality of commercial laying hens. Acta Scientiarum-Animal Sciences, 27(1), 35-41.

Keshavarz, K., \& Nakajima, S. (1993). Re-evaluation of calcium and phosphorus requirements of laying hens for optimum performance and eggshell quality. Poultry Science, 72(1), 144-153.

Laganá, C., Pizzolante, C. C., Togashi, C. K., Kakimoto, S. K., Saldanha, É. S. P. B., \& Álvares, V. (2011). Influência de métodos de debicagem e do tipo de bebedouro no desempenho e na qualidade dos ovos de codornas japonesas. Revista Brasileira de Zootecnia, 40(6), 1217-1221.

Lichovnikova, M. (2007). The effect of dietary calcium source, concentration and particle size on calcium retention, eggshell quality and overall calcium requirement in laying hens. British Poultry Science, 48(1), 71-75.

Lopes, I. R. V., Freitas, E. R., Lima, J. R., Viana Neto, J. L., Bezerra, R. M., \& Lima, R. C. (2011). Desempenho e qualidade dos ovos de poedeiras comerciais alimentadas com rações contendo farelo de coco tratado ou não com antioxidante. Revista Brasileira de Zootecnia, 40, 2431-2438.

Mazzuco, H., Kunz, A., de Paiva, D. P., Jaenisch, F. R. F., Palhares, J. C. P., de Abreu, P. G., Rosa, P. S., \& de Avila, V. S. (2006). Boas práticas de produção na postura comercial. Embrapa Suínos e Aves-Circular Técnica, 49, 1-39.

Mazzuco, H., Rosa, P. S., \& Jaenisch, F. R. F. (1998). Problemas de casca de ovos: identificando as causas. Embrapa Suínos e Aves-Documentos, 48, 1-20.

Menezes, P. C., Cavalcanti, V. F. T., Lima, E. R., \& Evêncio Neto, J. (2009). Aspectos produtivos e econômicos de poedeiras comerciais submetidas a diferentes densidades de alojamento. Revista Brasileira de Zootecnia, 38(11), 2224-2229.

Menezes, P. C., Lima, E. R., Medeiros, J. P., Oliveira, W. N. K., \& Evêncio-Neto, J. (2012). Egg quality of laying hens in different conditions of storage, ages and housing densities. Revista Brasileira de Zootecnia, 41(9), 2064-2069.

Molino, B., Berto, D. A., Pelícia, K., Osera, R. H., Edivaldo Antônio Garcia, A., Faitarone, G., \& Rafaela Hanae Osera, A. B. (2012). Desempenho e qualidade dos ovos de poedeiras comerciais alimentadas com semente de urucum (Bixa orellana L.) moída na dieta. Veterinária e Zootecnia, 16(4), 689-697.

NRC. (1994). Nutrients Requirements of Poultry (9th (ed.); 7th rev.). Natl. Acad. Press, Washington, DC.

Nunes, K. C., Garcia, R. G., Borille, R., Nääs, I. A., \& Santana, M. R. (2013). Led como fonte de luz na avicultura de postura. Enciclopédia Biosfera, 9(17), 1765-1782.

Oliveira, B. L., \& Oliveira, D. D. (2013). Qualidade e tecnologia de ovos. In Lavras: Editora UFLA (Universidade Federal de Lavras). Editora da Universidade Federal de Lavras.

Oliveira, C. A. F., Albuquerque, R., Correa, B., Kobashigawa, E., Reis, T. A., Fagundes, A. C. A., \& Lima, F. R. (2001). Produção e qualidade dos ovos de poedeiras submetidas à intoxicação prolongada com aflatoxina B1. Arquivos Do Instituto Biológico, 68(2), 1-4.

Oliveira, D. L., Nascimento, J. W. B., Camerini, N. L., Silva, R. C., Furtado, D. A., \& Araujo, T. G. P. (2014). Desempenho e qualidade de ovos de galinhas poedeiras criadas em gaiolas enriquecidas e ambiente controlado. Revista Brasileira de Engenharia Agrícola e Ambiental, 18(11), 1186-1191.

Oreng, R. E., \& Evans, J. S. (1990). Ciência e produção de aves: aquecimento, criação, alojamento, equipamentos e produção de aves. São Paulo: Roca, 143-178.

Pascoal, L. A. F., Bento Junior, F. A., Santos, W. S., Silva, R. S., Dourado, L. R. B., \& Bezerra, A. P. A. (2008). Qualidade de ovos comercializados em diferentes estabelecimentos na cidade de Imperatriz-MA. Revista Brasileira de Saúde e Produção Animal, 9(1), 150-157. 
Pavan, A. C., Garcia, E. A., Móri, C., Pizzolante, C. C., \& Piccinin, A. (2005). Efeito da densidade na gaiola sobre o desempenho de poedeiras comerciais nas fases de cria, recria e produção. Revista Brasileira de Zootecnia, 34(4), 1320-1328.

Pissinati, A., Oba, A., Yamashita, F., Silva, C. A., Pinheiro, J. W., \& Roman, J. M. M. (2014). Qualidade interna de ovos submetidos a diferentes tipos de revestimento e armazenados por 35 dias a $25^{\circ} \mathrm{C}$. Semina: Ciências Agrárias, 35(1), 531-540. https://doi.org/http://dx.doi.org/10.5433/16790359.2014v35n1p531.

Ramos, K. C. B. T., Camargo, A. M., Oliveira, É. C. D., Cedro, T. M. M., \& Morenz, M. J. F. (2012). Avaliação da idade da poedeira, da temperatura de armazenamento e do tipo embalagem sobre a qualidade de ovos comerciais. Revista de Ciências Da Vida, 30(2), 12. https://doi.org/http://ufrrj.br/SEER/index.php?journal=rcv\&page=article\&op=view\&path\%5B\%5D $=741 \&$ path $\% 5 \mathrm{~B} \% 5 \mathrm{D}=485$.

Ronchi, C. (2004). Principais práticas de manejo para aves recém nascidas. Editora Animal World, 1(6), 26-30.

Sechinato, A. S., Albuquerque, R., \& Nakada, S. (2006). Efeito da suplementação dietética com micro minerais orgânicos na produção de galinhas poedeiras. Brazilian Journal of Veterinary Research and Animal Science, 43(2), 159-166.

Silva, E. M. C., Dourado, L. R. B., \& Merval, R. R. (2012). Medidas para avaliar o conforto térmico em aves. PUBVET, 6, Art. 1450-1454.

Silva, J. H. V., \& Santos, V. J. (2000). Efeito do carbonato de cálcio na qualidade da casca dos ovos durante a muda forçada. Revista Brasileira de Zootecnia, 29(5), 1440-1445.

UBA. (2008). Protocolo de boas práticas de produção de ovos. Disponível em: <http:// http://www.avisite.com.br/legislacao/anexos/protocolo_de_boas_praticas_de_produc ao_de_ovos.pdf> Acesso em: 31 de outubro de 2019

Van Den Brand, H., Parmentier, H. K., \& Kemp, and B. (2004). Effects of housing system (outdoor vs cages) and age of laying hens on egg characteristics. British Poultry Science, 45(6), 745-752.

Vieira, R. S. A., \& Bertechini, A. G. (2001). Desempenho e qualidade de ovos de poedeiras comercias alimentadas com rações contendo fitase. Ciência e Prática, 25(6), 836-841.

Vilela, D. R. (2012). Qualidade interna e externa de ovos de poedeiras comerciais com casca normal e vítrea. Ciência Animal Brasileira, 17(4), 509-518. https://doi.org/http://dx.doi.org/10.1590/10896891 v17i421535.

Vitorasso, G., \& Pereira, D. F. (2009). Análise comparativa do ambiente de aviários de postura com diferentes sistemas de acondicionamento. Revista Brasileira de Engenharia Agrícola e Ambiental, 13(6), 788-794.

Recebido: 06 de novembro, 2019.

Aprovado: 04 de dezembro, 2019.

Publicado: 22 de abril, 2020.

Licenciamento: Este artigo é publicado na modalidade Acesso Aberto sob a licença Creative Commons Atribuição 4.0 (CC-BY 4.0), a qual permite uso irrestrito, distribuição, reprodução em qualquer meio, desde que o autor e a fonte sejam devidamente creditados. 